IRA-International Journal of Applied Sciences ISSN 2455-4499; Vol.03, Issue 03 (2016)

Institute of Research Advances

http://research-advances.org/index.php/IRAJAS

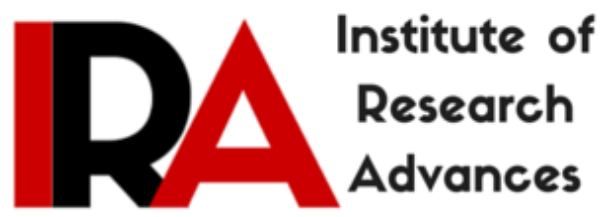

\title{
Occurrence of SHV GENE and Antibiogram of Klebsiella Pneumoniae Infection in Swiss Albino Mice Colony
}

${ }^{1}$ M. Thangapandiyan: Deptt. of Veterinary Pathology

${ }^{2}$ S. P. Preetha: Deptt. Veterinary Pharmacology \& Toxicology

${ }^{3}$ S. Suresh Kannan: Deptt. Veterinary Microbiology

${ }^{4}$ T. Mohanapriya: Deptt. of Veterinary Pathology

1,2,3,4 Madras Veterinary College,

Tamil Nadu Veterinary and Animal Sciences University, Chennai - 600 051- India.

DOI: http://dx.doi.org/10.21013/jas.v3.n3.p18

\section{How to cite this paper:}

Thangapandiyan, M., Preetha, S., Kannan, S., \& Mohanapriya, T. (2016).

Occurrence of SHV GENE and Antibiogram of Klebsiella Pneumoniae Infection in Swiss Albino Mice Colony. IRA-International Journal of Applied Sciences (ISSN 2455-4499), 3(3). doi:http://dx.doi.org/10.21013/jas.v3.n3.p18

(C) Institute of Research Advances

(cc) EY-NC

This works is licensed under a Creative Commons Attribution-Non Commercial 4.0 International License subject to proper citation to the publication source of the work.

Disclaimer: The scholarly papers as reviewed and published by the Institute of Research Advances (IRA) are the views and opinions of their respective authors and are not the views or opinions of the IRA. The IRA disclaims of any harm or loss caused due to the published content to any party. 


\section{ABSTRACT}

An epizootic causing high morbidity and high mortality in Swiss albino inbred mice over a period of two weeks caused by Klebsiella pneumoniae is reported. Diagnosis was based on clinical signs, histopathological, bacteriological evaluation of the lung, kidney and intestinal tissue and multiplex PCR. Biochemical tests were positive for citrate, nitrate, urease, lysine decarboxylase, ornithine decarboxylase and negative for phenylalanine and hydrogen sulphide production. Carbohydrates viz., glucose, lactose, adonitol, arabinose were fermented but sorbitol was not. Disc diffusion tests for antibiotic sensitivity showed susceptibility to enrofloxacin, amikacin, doxycyline and resistant to cephalexin, cefadroxil, cefuroxime, cephtriaxone and ampicillin. Amplification by multiplex PCR for sulphydryl variable (SHV) gene yielded a product size of $472 b p$.

Key words: Mice, Klebsiella sp, pneumonia, antibiogram

\section{INTRODUCTION:}

Lower respiratory tract infections have always remained a cause of concern for medical fraternity throughout the world. Klebsiella pneumoniae is commonly associated with both community acquired and nosocomial pneumonia resulting in severe lung infection with high morbidity and high mortality rates or establishment of chronic pneumonia in untreated cases [1].

Reports of clinical disease in immunocompetent rodents are rare and $K$. pneumoniae is therefore considered an opportunistic pathogen. The organism has been implicated in several pathologies of the respiratory and urinary systems [2]. Moreover, pulmonary infections due to Klebsiella pneumoniae are often complicated by multilobular involvement, lung abscesses and gangrene. Biochemical identification deemed necessary in order to distinguish from other members of Klebsiella sp. Presence of sulphydryl variable (SHV) gene in Klebsiella pneumoniae confers resistance to the prevailing $\beta$ - lactam antibiotics.

\section{MATERIALS AND METHODS:}

\section{Specimens:}

Over a period of two weeks necropsies were performed on 44 inbred swiss albino mice that had died out of a group of 500 mice aged 1 to 15 months, maintained in an animal breeding unit. The environment of the animal house was, temperature $23-25^{\circ} \mathrm{C}$, relative humidity $50-60 \%$ with $12-12$ lighting system.

\section{Bacteriological evaluation:}

Representative samples were taken from the tissues exhibiting gross changes. Exudates from lung, kidney and intestine were obtained with sterile swabs (Hi-Media, Mumbai) and were inoculated in duplicate on to MacConkey agar plates aerobically at $37^{\circ} \mathrm{C}$ for 18 hours. After 18 hours of post inoculation, a small colony growth was smeared on grease free microscopic glass slide and stained with Grams stain. Biochemical characterization was done with KB002 HiAssorted Biochemical Test Kit for gram negative rods, Hi-Media, Mumbai, India. For antimicrobial susceptibility testing, isolates were assayed for the zone size criteria by the disk diffusion method on Mueller Hinton agar (Hi-Media, India) following the recommendations of National Committee for 
Clinical Laboratory Standards. Antibiotics tested include ampicillin $(\mu \mathrm{g})$, cephatriaxone, cephalexin, amikacin, enrofloxacin and doxycycline.

\section{Histological procedures:}

Portions of lung, kidney and intestinal tissues were fixed in $10 \%$ formalin, processed and sections were cut at $5 \mu \mathrm{m}$ thickness, stained with haematoxylin and eosin $(\mathrm{H} \& \mathrm{E})$. The sections were then viewed under light microscope (Nikon microscope, Japan) for histopathological changes.

\section{PRIMERS FOR SHV GENE:}

\section{AMPLIFICATION OF SHV GENE:}

Genomic DNA was prepared from overnight cultures grown on Luria-Bertani (LB) medium (Hi-Media laboratories Pvt.Ltd, Mumbai) by inoculating a single colony into $100 \mu \mathrm{l}$ of double distilled water, boiling at $95^{\circ} \mathrm{C}$ for $10 \mathrm{~min}$. Equal volume of chloroform:isoamyl alcohol (24:1 v/v) was added, centrifuged at $8000 \mathrm{~g}$ for $15 \mathrm{~min}$. The upper layer was used as crude DNA. Amplification reactions for SHV gene was performed in a $25 \mu 1$ of 10X PCR reaction buffer with $\mathrm{Mgcl}_{2}(15 \mathrm{mM}), 0.5 \mu 1(200 \mu \mathrm{M})$, deoxynucleoside triphosphate mix (dNTPs, $10 \mathrm{mM}), 0.5 \mu \mathrm{l}$ of the primer $(10 \mathrm{pm} / \mu \mathrm{l})$ with $0.5 \mu \mathrm{l}(3 \mathrm{U} / \mu \mathrm{l}) \mathrm{Taq}$ DNA polymerase (Bangalore Genie, India). Five microlitres of the template DNA preparation was added to the reaction mixture and was carried out on My Cycler DNA thermal cycler (BioRad, Australia). After initial denaturation at $94^{\circ} \mathrm{C}$ for 2 min, reaction was performed in a 3 step cycling condition of denaturation for 25 cycles of $1 \mathrm{~min}$ at $95^{\circ} \mathrm{C}$, annealing at $52^{\circ} \mathrm{C}$ for $55 \mathrm{sec}$ and extension at $72^{\circ} \mathrm{C}$ for $45 \mathrm{sec}$. Final extension was carried out at $72^{\circ} \mathrm{C}$ for $5 \mathrm{~min}$. The resulting products were analysed by electrophoresis with $1.5 \%$ agarose gels in Tris-borate-EDTA buffer (TBE; Gibco, NY, USA). The gels were stained with ethidium bromide and the band observed at the desired position was photographed on an ultraviolet light transilluminator [3].

\section{RESULTS:}

Clinical signs were inappetance, pyrexia, ruffled hair coat and hunched back. Grossly, severe congestion and multiple areas of consolidation occurred in all the lung lobes. Cervical and thoracic lymphadenopathies were noted along with multiple disseminated abscess of 1-2 mm diameter in both the kidney cortices. Histologically, lung and kidney revealed multifocal necrotic areas containing clumps of gram positive slender bacilli and invading into the parenchyma. Certain necrotic areas were surrounded by fibrin strands and infiltrated by polymorphonuclear cells. Necropsy results weren't encouraging in this case because of post mortem autolysis. Grossly, there was severe congestion and multiple areas of consolidation in all the lung lobes. Microscopically, multifocal necrotic lesions in lung and kidney were noticed containing clumps of gram negative slender bacilli.

Bacteriologically, colonies were coalescent, mucoid, lactose fermenting, pink type, non motile and measuring 3-8 $\mathrm{mm}$ in diameter. Post inoculation of the exudates, the colony characters were identified as coalescent mucoid, lactose fermenting, pink type measuring 3-8 $\mathrm{mm}$ in diameter. Colonies were defined based on the string like growth attached to the loop as it was lifted vertically from the agar plate. Biochemical characters of the non motile isolates tested positive for citrate and nitrate and negative for phenylalanine and hydrogen sulphide production. Carbohydrates viz., glucose, lactose, adonitol, arabinose 
were fermented but sorbitol was not. Since the organism produced urease and lysine decarboxylase, it also tested positive for ornithine decarboxylase.

Disc diffusion test results showed susceptibility to enrofloxacin, amikacin, doxycyline and resistant to cephalexin, cephtriaxone, cefadroxil, cefuroxime and amoxicillin with clavulanic acid. Further, isolates of Klebsiella pneumoniae expressed SHV gene, the gene that confers resistance to cephalosporins and monobactams. The amplified product of SHV gene with a product size of $472 \mathrm{bp}$ (lane 3) corresponded to 200bp molecular weight marker in lane 1 and the reference sample (Klebsiella pneumoniae ATCC 700603) in lane 5.

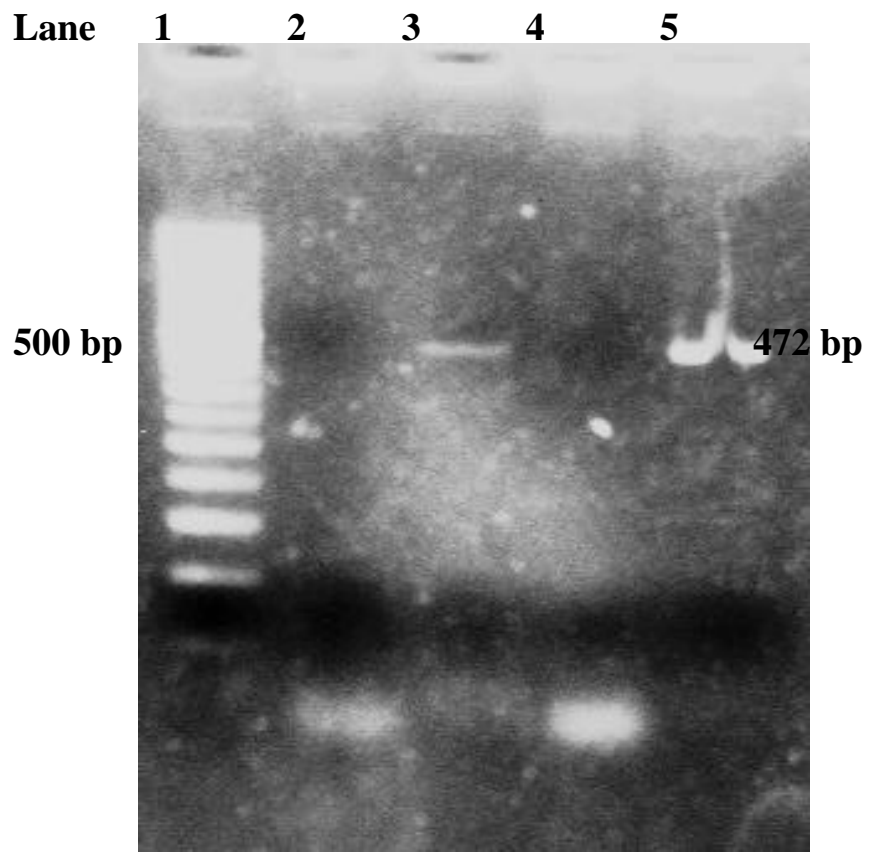

Fig.1. PCR amplification of SHV gene, Lane 1: 200bp ladder, Lane 3: Sample, Lane 4: Negative control, Lane 5: Klebsiella pneumoniae ATCC 700603, reference positive control.

\section{DISCUSSION:}

Mice and rats experimentally infected with K. pneumoniae serve as models for a variety of diseases including pneumonia, endotoxaemia, sepsis, cystitis and pyolenephritis [4]. However, reports of naturally occurring infectious diseases in rodents due to Klebsiella spp. are very infrequent [5].

The severity of a lung infection is primarily determined by the virulence of the infecting strain. Initially, authors [6] described bronchopneumonia in rats, by intranasal inoculation of bacteria, but they eventually abandoned their model due to high mortality in the early phase of infection. Chronic pulmonary infection in mice by $K$. pneumoniae has so far been reported only by researchers [7]. These workers observed a marked variation in susceptibility of a mouse strain to an experimental respiratory tract infection, besides high mortality towards the later part of observation period. In all these reports, experimental animals were exposed to only one infection dose of $K$. pneumoniae. Chronic abscess formation with fibroblastic proliferation around the bronchioles and 
alveolar destruction at certain places was noted. Maximum tissue destruction was also demonstrable, through high generation of MDA and $\mathrm{LDH}$, in the lungs of infected animals.

Klebsiella spp. are capable of producing a prominent capsule composed of complex acidic polysaccharides, which are likely major determinants of pathogenicity, at least for K. pneumoniae [8]. Antimicrobial susceptibility testing showed that 90 per cent of isolates were resistant to at least one of the 3rd generation cephalosporins (3GC). This resistance is mainly associated with the production of enzymes called Temoniera and sulphydryl variable $(S H V)$ that are generally plasmid-mediated [9]. The disk diffusion method does not allow routine differentiation of strains producing these enzymes. Molecular methods, like PCR need to be used for the differentiation of b-lactamaseproducing isolates. Our findings showed that majority of isolates carried $S H V$. Studies from other parts of the world reported that $S H V-5$ gene was common in $K$. pneumoniae isolates.

In conclusion, we recorded an outbreak of $K$. pneumoniae infection induced moratlity in swiss albino mice. The organism was resistant to most of the $3 \mathrm{GCs}$ but sensitive to enrofloxacin, doxicycline and amikacin. Multiplex PCR on the isolates of Klebsiella pneumoniae expressed SHV gene, the gene that confers resistance to cephalosporins and monobactams.

\section{References:}

1. Sharma, S., Chhibber,S., Mohan,H and Sharma,S. (2012) Induction of chronic pneumonia in normal mice by Klebsiella pneumonia. Am. J. Biomed. Sci., 4(2): 102-110.

2. Jackson, N.N, Wall, H.G., Miller, C.A. and Rogul, M. (1980) Naturally acquired infections of Klebsiella pneumoniae inWistar rats. Lab. Anim., 14, 357-61.

3. Lal, P., Kapil.A., Das,B.K. and Sood,S. (2007) Occurrence of TEM \& SHV gene in extended spectrum b-lactamases (ESBLs) producing Klebsiella sp. isolated from a tertiary care hospital. Indian J. Med. Res., 2: 173-178.

4. Baker, D.G. (1998) Natural pathogens of laboratory mice, rats, and rabbits and their effects on research. Clin. Microbiol. Rev., 11: 231-66.

5. Bleich,A., Kirsch, P., Sahly,H., Fahey.J., Smoczek.A., Hedrich.H.J., and Sundberg.J.P. (2008) Klebsiella oxytoca: opportunistic infections in laboratory rodents. Lab. Anim., 42:369-375.

6. Berendt, R.F., Long, G.G., Abeles, F.B., Canonico, P.G., Elwell, M.R. and Powanda, M.C. (1977) Pathogenesis of respiratory Klebsiella pneumoniae infection in rats: bacteriological and histological findings and metabolic alterations. Infect. Immun., 15: 586-593.

7. Lizawa, Y., Nischi, T., Kondo, M. and Imada, A. (1998) Experimental chronic pulmonary infection in mice caused by Klebsiella pneumoniae. Microbiol. Immunol., 32: 895-906.

8. Podschun, R. and Ullmann, U. (1988) Klebsiella spp. as nosocomial pathogens: epidemiology, taxonomy, typing methods, and pathogenicity factors. Clin. Microbiol. Rev.,11: 589-603.

9. Philippon A, Ben Redjeb S, Fournier G. and Ben Hassen A. (1989) Epidemiology of extended spectrum b-lactamases. Infection. 17 : 347-54. 